16

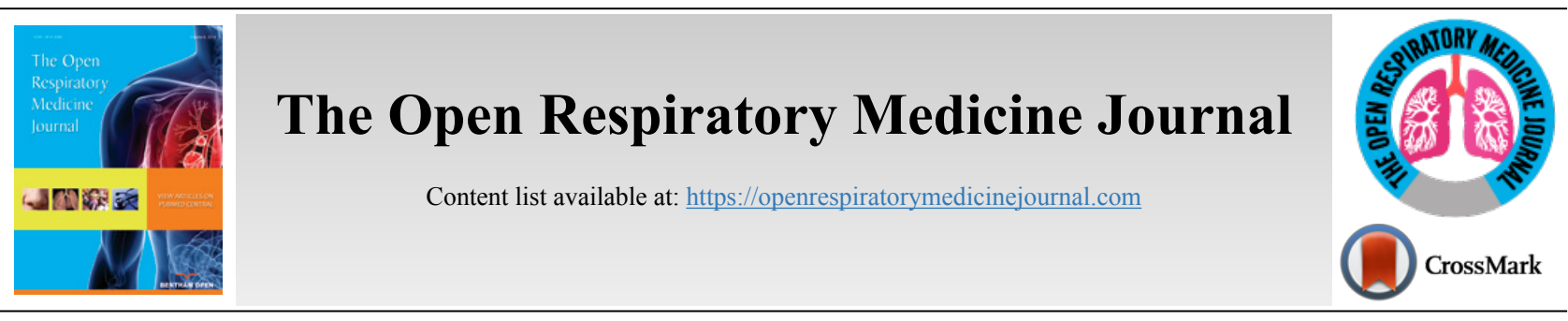

RESEARCH ARTICLE

\title{
Evaluation of Prognostic Factors Associated with Postoperative Complications Following Pulmonary Hydatid Cyst Surgery
}

\author{
Mojtaba Ahmadinejad ${ }^{1}$, Mozaffar Hashemi ${ }^{2, *}$ and Nasim Azizallahi ${ }^{3}$ \\ ${ }^{\prime}$ Department of General Surgery, Alborz University of Medical Sciences, Karaj, Iran \\ ${ }^{2}$ Department of General Surgery, Isfahan University of Medical Sciences, Isfahan, Iran \\ ${ }^{3}$ Department of Microbiology, Alborz University of Medical Sciences, Karaj, Iran
}

\begin{abstract}
:
Background:

Hydatid cysts are one of the serious complications following echinococcus infection. The liver and the lungs are the most affected organs, respectively. The severity of the disease is associated with the increase in the number and the size of the cysts, cysts rupture, and systemic effects. The aim of this study is to evaluate prognostic factors that are associated with the increased incidence of postoperative complications following pulmonary hydatid cyst surgery.

Methods:

Patients referred to Madani hospital from 2014-2018, presenting pulmonary hydatid cysts were included in this study. All the patients were evaluated based on the following parameters: age, gender, location and size of the cysts, rupture status of the cysts (intact or perforated), type of surgical intervention (capitonnage or segmentectomy) and Erythrocyte Sedimentation Rate (ESR). The factors were then compared with postoperative complications. Statistical analysis of the data obtained was conducted using R-software

Results:

Of 76 patients enrolled in our study, $52.63 \%$ were males and $47.36 \%$ were female. Air leak complication was reported in $13.15 \%$ of the patients and $3.94 \%$ of the patients were presented with pleural effusion. Postoperative complications were significantly associated with the perforated (ruptured) cysts $\mathrm{p}=0.001$, segmentectomy $\mathrm{p}=0.013$, giant hydatid cysts $\mathrm{p}=0.007$ and ESR $\mathrm{p}=0.014$. However, the side of the lung was not significantly related to postoperative complications.

Conclusion:

Our study reports that perforated cysts, increased size, segmentectomy and abnormal ESR are likely to increase postoperative complications following pulmonary hydatid cysts surgery. Prospective studies with perioperative parameters and greater sample size can help to deduce better inferences.
\end{abstract}

Keywords: Hydatid cyst, Segmentectomy, Pulmonary, Postoperative complications, ESR, pulmonary.

\section{Article History}

Received: January 14, 2020

Revised: April 17, 2020

Accepted: April 30, 2020

\section{INTRODUCTION}

Hydatid cyst/Hydatid Disease (HD) is one of the most common lung parasitic infections, as a result of echinococcosis. The zoonotic infection is mostly caused by the echinococcus granulosus parasite in the larval stage belonging to the Taeniidae family and Echinococcus genus. It is known to affect 1 million people worldwide [1]. The liver and the lungs are the

* Address correspondence to this author at the Department of General Surgery, Isfahan University of Medical Sciences, Isfahan, Iran; Tel: 09123961984;

Email: md.mozaffarhashemi@gmail.com most affected organs. The eggs of the parasite, when acquired from uncooked food, drinking water, host animals, or soil containing the eggs, by means of portal circulation, settle into the liver. Furthermore, through the portal vein and inferior vena cava, they reach the heart and the lungs, eventually. Lymphatic pathways, venal-venous anastomosis, and direct inhalation of the eggs are also the possible routes of the entrance of the eggs into the lungs [2, 3]. Pulmonary hydatid cysts are diagnosed by means of imaging modalities, lab findings and patients' history [3]. 
Several variations have been reported in regard to the prevalence of HD in the Middle East [4]. However, in Iran, the pooled prevalence of the infection is reported to be $23.6 \%$, where, southern part, rural area and female gender are more infected [5]. Echinococcus granulosus infects about $92.75 \%$ of these cases [6].

The studies have indicated that several cysts-associated factors are likely to increase postoperative complications of the infection. Furthermore, organ-specific and systemic complications are also associated with intact and ruptured cysts, location and the size of the cysts [7]. Surgical intervention is, therefore, required for the removal of cysts. Delay in the surgery may also lead to increased hospitalization costs and duration [8].

The aim of this study is to investigate prognostic factors associated with postoperative complications following pulmonary hydatid cysts surgery.

\section{METHODS}

In this cross-sectional study, patients presenting pulmonary hydatid cyst referred to Madani hospital were included. Patients with bilateral lung cysts, history of previous treatments and those who denied undergoing surgery, were excluded from this study.

All the patients were briefed about the surgical details and written consents were obtained. The study was approved by the Ethical committee of the Madani hospital.

Preoperative corticosteroids were given to the patients to avoid anaphylactic shock. All surgical procedures were conducted under general anesthesia. The patients underwent posterolateral thoracotomy from $5^{\text {th }}, 6^{\text {th }}$ or $7^{\text {th }}$ intercostal space, depending on the location of the cysts and the cysts were contained with gas and $20 \%$ of sodium chloride solution. As per the location, size and number of the cysts, desired surgical procedures were performed.

Based on the data of previous studies $[9,10]$, the following variables were included in the study: age, gender, the condition of the cysts (intact/rupture or perforated), the size and the location of the cysts, the type of surgical intervention (cystostomy, bronchial closure and capitonnage or segmentectomy), postoperative complications and erythrocyte sedimentation rate. Patients were followed up for a month for postoperative complications such as rupture, air leak, pleural effusion, empyema and hemoptysis

\section{STATISTICAL ANALYSIS}

Since the dependent variable (complication status) in this study was qualitative, contingency tables and mosaic charts were used to describe the relationship of the independent variables with complication status. Risk difference (RD) indices were also used to measure the relationship. RD index refers to the difference in complication rate with the subgroups of independent variables in the study. The reason for using the $\mathrm{RD}$ index in this study is a few numbers of reported adverse events in the subgroup of independent variables. Fisher's exact test and two-sample comparison test were also used. The significance level was set at 0.05 and statistical analysis was performed using R-software.

\section{RESULTS}

Of 76 pulmonary hydatid cyst patients included in the study, $40(52.63 \%)$ were male and $36(47.36 \%)$ were female. The mean age of the patients included was $32 \pm 12.2$ (minimum 8 years and maximum 68 years). The right lobe lower lobe was the most affected area, reported in 55 patients (72.36\%).

The most common postoperative complication was air leak, $n=10(13.15 \%)$, followed by 3 cases $(3.94 \%)$ of pleural effusion. No postoperative mortality was reported among these patients.

\subsection{Rupture Variable}

Fisher exact test showed that there was a significant relationship between rupture status and postoperative complications ( $\mathrm{p}$-value $=0.001)$. The incidence of complications for patients with rupture was 33 times higher than for patients without rupture Table 1.

Table 1. The relationship between the variable state of rupture and complications status.

\begin{tabular}{|c|c|c|}
\hline P value & Alternative Hypothesis & Odds Ratio \\
\hline $0.001186 * *$ & two.sided & 33.2 \\
\hline
\end{tabular}

The RD index was reported to be 0.34 , indicating that the prevalence of complications in patients with rupture was $34 \%$, which is significantly higher than in patients without rupture ( $p$-value $=0.016$ ). The mosaic Fig. (1) below illustrates these findings.

\subsection{Surgery Type Variable}

There was a significant relationship between the type of surgery and complication status ( $p$-value $=0.006)$. The odds ratio for this variable cannot be calculated because the frequency of one of the cells is zero Table 2.

Table 2. The relationship between the type of surgery and the complication status.

\begin{tabular}{|c|c|c|}
\hline P value & Alternative Hypothesis & Odds Ratio \\
\hline $0.006428 * *$ & two.sided & Inf \\
\hline
\end{tabular}

The RD index was 0.17 , which indicates that the incidence of complications in patients undergoing segmentectomy was $17 \%$ higher than in patients undergoing capitonnage surgery. This difference was reported to be statistically significant ( $\mathrm{p}$ value $=0.013$ ). The mosaic Fig. (2) below illustrates the outcomes from Fisher's test.

\subsection{Size Variable}

The results showed that the relationship between size and complication status was significant ( $p$-value $<0.001$ ). The chance of complications for patients with rupture was 33 times higher than for patients without rupture Table 3 . 


\section{Complication}

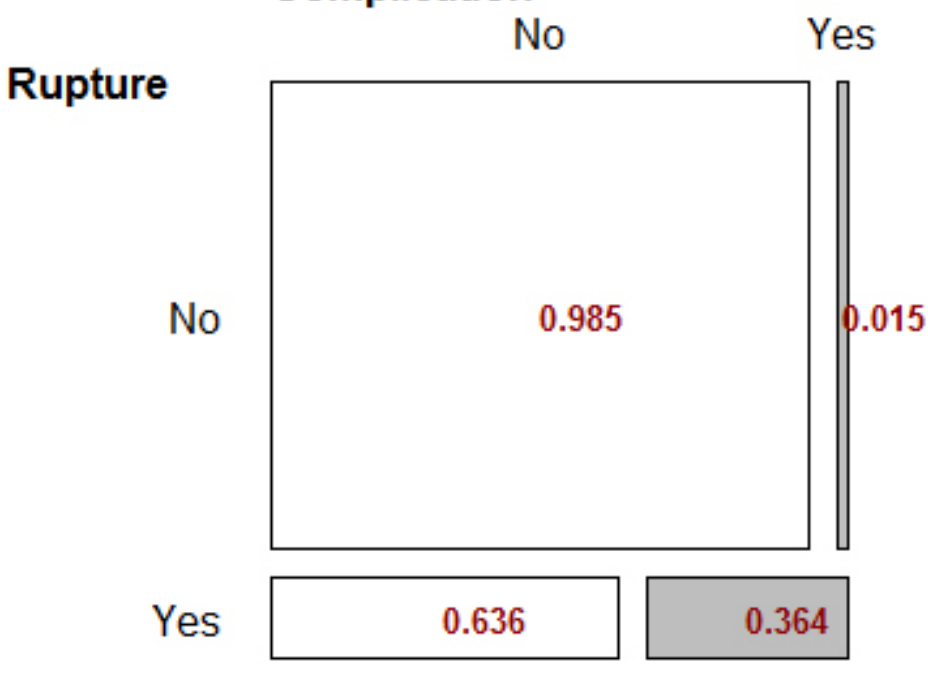

Fig. (1). Fisher's Exact Test for Rupture variable.

\section{Complication}

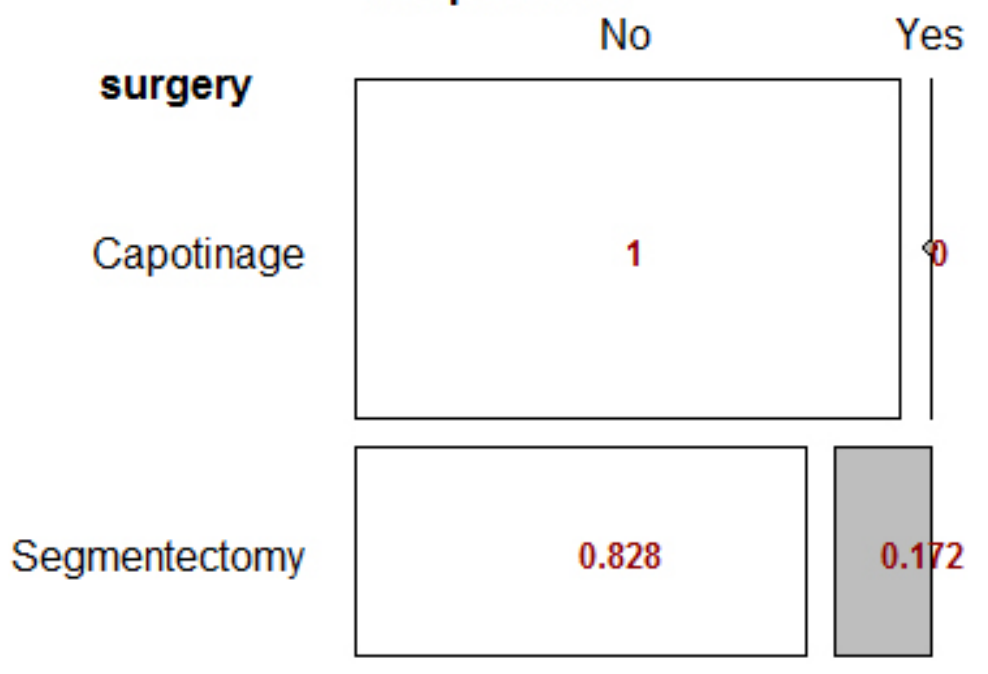

Fig. (2). Fisher's Exact Test for surgery type variables.

Table 3. Size correlation with complication status.

\begin{tabular}{|c|c|c|}
\hline P value & Alternative Hypothesis & Odds Ratio \\
\hline $0.0002364 * * *$ & two.sided & Inf \\
\hline
\end{tabular}

The RD index was found to be 0.31 , indicating that the prevalence of complications in patients with cyst greater than $10 \mathrm{~cm}$ was $31 \%$ higher. The difference was also reported to be statistically significant. ( $p$-value $=0.007$ ), as shown in Fig. (3).

\subsection{Lung Side Variable}

The LR subgroup was excluded from the Lung side because of its low frequency. Outcomes showed that there was no significant relationship between lung position variable and the complication status ( $\mathrm{p}$-value $=0.61$ ).
The RD index was found to be 0.05 , indicating that the prevalence of complications in patients with left lung involvement was not significantly different from patients with right lung disease ( $p$-value $=0.3$ ), as shown in Fig. (4).

\subsection{ESR Variable}

The results showed that the relationship between ESR status and complication status was significant $(p$-value $=0.009)$ Table 4.

Table 4. The relationship between the ESR variable and the complication status.

\begin{tabular}{|c|c|c|}
\hline P value & Alternative Hypothesis & Odds Ratio \\
\hline $0.009197 * *$ & two.sided & Inf \\
\hline
\end{tabular}


The RD index of ESR and complication status was 0.161, indicating that the prevalence of complications in patients with abnormal ESR was $16 \%$ higher than in patients with normal ESR. The difference was reported to be statistically significant $(p$-value $=0.014)$ in Fig. (5).

\section{DISCUSSION}

Our study investigated the association of postoperative complications with the size and the rupture status of the cysts, along with the type of surgical intervention, side of the lung and erythrocyte sedimentation rate. We reported that the size, rupture of the cysts, the type of the surgery and abnormal ESR levels were significantly associated with increased postoperative complications. Similar to the results from Sadrizadeh, Haghi [3] study, the most common postoperative complication reported in our study was an air leak.

When comparing capitonnage with segmental resection of the cysts, the former is associated with reduced postoperative airway leak and empyema formation and excellent postoperative outcomes [11]. The findings from our study indicate similar outcomes. The significant difference in the postoperative complication was seen between the two surgical procedures; greater in the segmental resection group. However, in an early study, Turna, Y1lmaz [12] reported no additional advantage of capitonnage on the postoperative complication and the duration of the hospitalization.

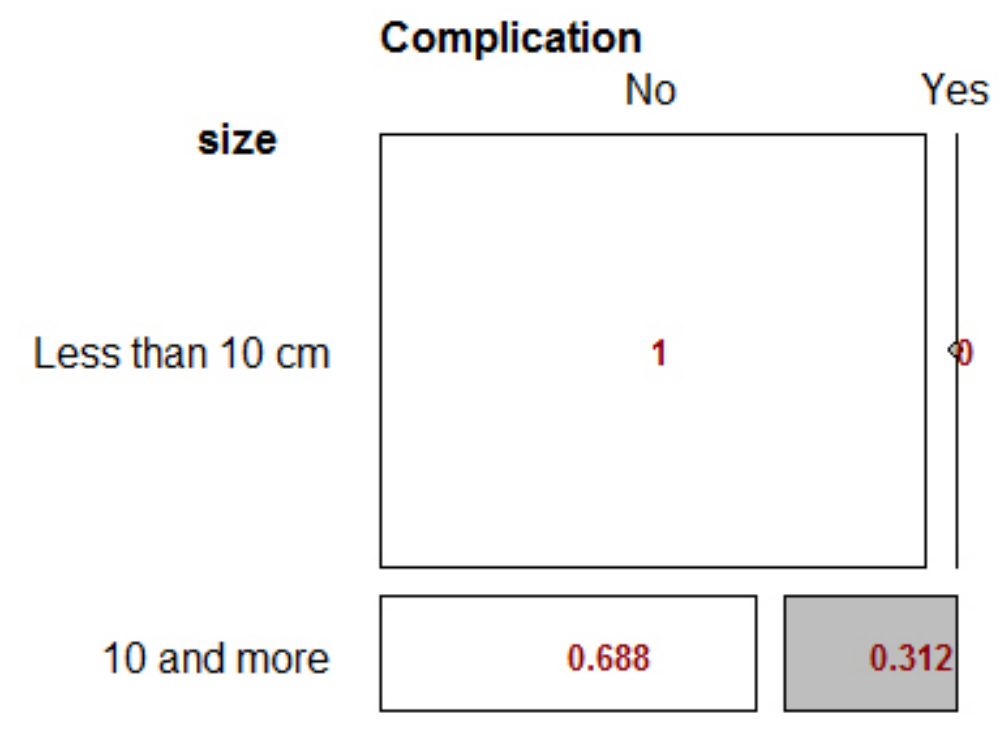

Fig. (3). Fisher's Exact Test for size variable.

\section{Complication}

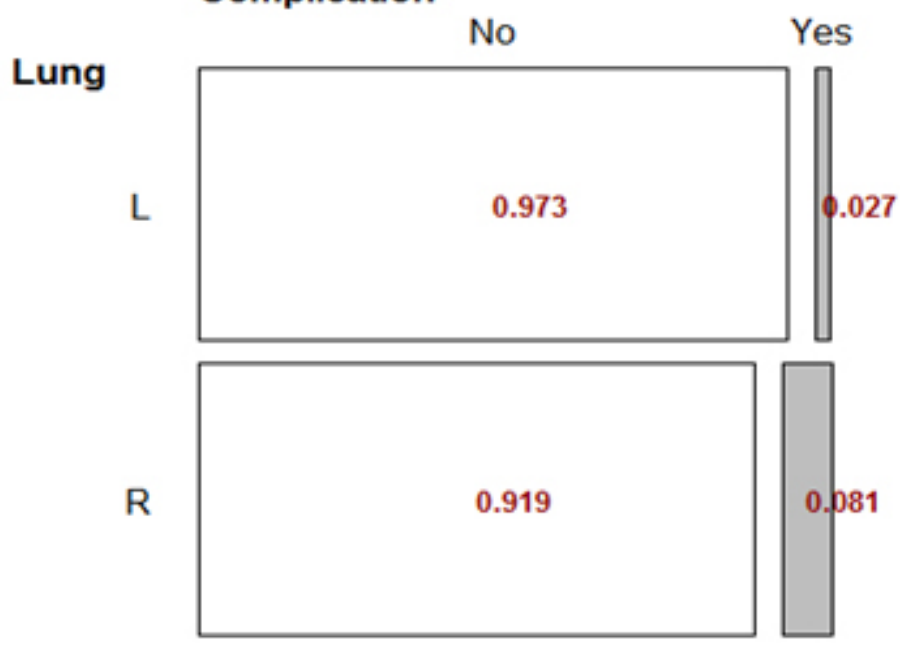

Fig. (4). Fisher's Exact Test for Lung side variable. 


\section{Complication}

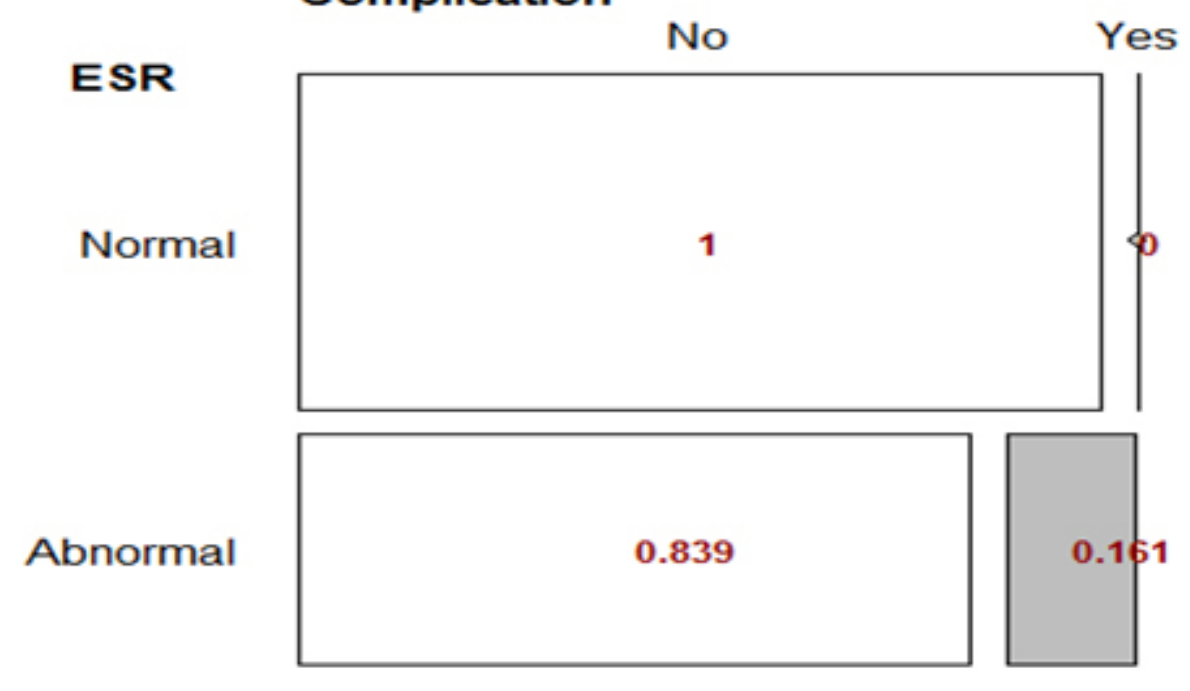

Fig. (5). Fisher's Exact Test for ESR variable.

It is also indicated that the large size of the cysts places pressure on surrounding organs such as the heart, esophagus and trachea and is thereby known to be presented with a greater deal of the complications [8]. Moreover, giant hydatid cysts $>$ $10 \mathrm{~cm}$ provide surgical challenges. Postoperatively, giant cysts may also be associated with a greater incidence of complications [13], such as air leak [14] and empyema [15]. The sample size of these studies varies massively from that of ours. Furthermore, the data in our study have not been presented with respect to the age group; nonetheless, we report that giant hydatid cysts can significantly lead to increased postoperative complications.

Onal and Demir [7] reported that perforated hydatid cysts lead to increased risk of postoperative complications such as atelectasis, pneumothorax, and broncho-pleural fistula, as compared to intact cysts. Our study reported similar findings; however, most common of all the complications were air leak and pleural effusion.

An increased erythrocyte sedimentation rate is commonly reported in patients presenting HD [16]. Salama, Othman [17] reported that an elevation in ESR along with eosinophilia can be the indicator of multiple-organ involvement and complications such as rupture. Our study presents that increased levels of ESR were significantly correlated with an increased incidence of postoperative complications.

\section{CONCLUSION}

Our study is restricted to some limitations, which include; relatively smaller sample size, compared to other studies, lack of age and gender-based analysis and the use of the single dependent variable, i.e., postoperative complications.

The study concludes that advancement in the pathogenesis of the infection, characterized by increased cysts size and perforation of cysts, can lead to surgical challenges and increased incidence of postoperative complications.

Furthermore, segmentectomy can lead to an increased risk of these complications. Patients suspected of the infection are required to undergo an immediate diagnosis and treatment plan in order to reduce systemic effects and surgical adverse.

\section{ETHICS APPROVAL AND CONSENT TO PARTI- CIPATE}

The study was approved by the Ethical committee of the Madani Hospital, Iran under approval no. IR.ABZUMS. REC.1398.

\section{HUMAN AND ANIMAL RIGHTS}

All procedures performed in this study involving human participants were in accordance with the ethical standards of the institutional and/or national research committee and with the 1964 Helsinki declaration and its later amendments or comparable ethical standards.

\section{CONSENT FOR PUBLICATION}

Informed written consents were taken from all the patients when they were enrolled.

\section{AVAILABILITY OF DATA AND MATERIALS}

Not applicable.

\section{FUNDING}

None.

\section{CONFLICT OF INTEREST}

The authors deny any conflict of interest in any terms or by any means during the study-all the fees provided by the research center fund and deployed accordingly.

\section{ACKNOWLEDGEMENTS}

Declared none.

\section{REFERENCES}

[1] Agudelo Higuita NI, Brunetti E, McCloskey C. Cystic echinococcosis. J Clin Microbiol 2016; 54(3): 518-23. 
[http://dx.doi.org/10.1128/JCM.02420-15] [PMID: 26677245]

[2] Sarkar M, Pathania R, Jhobta A, Thakur BR, Chopra R. Cystic pulmonary hydatidosis. Lung India 2016; 33(2): 179-91. [http://dx.doi.org/10.4103/0970-2113.177449] [PMID: 27051107]

[3] Sadrizadeh A, Haghi SZ, Masuom SH, Bagheri R, Dalouee MN. Evaluation of the effect of pulmonary hydatid cyst location on the surgical technique approaches. Lung India 2014; 31(4): 361-5. [http://dx.doi.org/10.4103/0970-2113.142118] [PMID: 25378844]

[4] Himsawi N, Hijjawi N, Al-Radaideh A, Al-Tamimi M. Seroprevalence of cystic echinococcosis in a high-risk area (Al-Mafraq Governorate) in Jordan, using indirect hemagglutination test. Parasite Epidemiol Control 2019; 5: e00104-4. [http://dx.doi.org/10.1016/j.parepi.2019.e00104] [PMID: 31049423]

[5] Khalkhali HR, Foroutan M, Khademvatan S, et al. Prevalence of cystic echinococcosis in Iran: a systematic review and meta-analysis. J Helminthol 2018; 92(3): 260-8. [http://dx.doi.org/10.1017/S0022149X17000463] [PMID: 28589871]

[6] Khademvatan S, Majidiani H, Foroutan M, Hazrati Tappeh K, Aryamand S, Khalkhali HR. Echinococcus granulosus genotypes in Iran: a systematic review. J Helminthol 2019; 93(2): 131-8. [http://dx.doi.org/10.1017/S0022149X18000275] [PMID: 29606162]

[7] Onal O, Demir OF. The relation between the location and the perforation rate of lung hydatid cysts in children. Asian J Surg 2018; 41(5): 422-6.

[http://dx.doi.org/10.1016/j.asjsur.2017.04.001] [PMID: 28428006]

[8] Cobanoglu U, Asker S. Complications of Hydatid Cysts in the Lung. J Surg Surgical Res 2015; 1(2): 023-8. [http://dx.doi.org/10.17352/2455-2968.000006]

[9] Oruç $\mathrm{M}$, et al. Comparison of demographical characteristics, prognostic factors, and surgical outcomes in children and adult patients with pulmonary hydatid cyst. Eurasian J Pulmonol 2017; 19 [http://dx.doi.org/10.5152/ejp.2017.95866]

10] Akcan A, Sozuer E, Akyildiz H, Ozturk A, Atalay A, Yilmaz Z. Predisposing factors and surgical outcome of complicated liver hydatid cysts. World J Gastroenterol 2010; 16(24): 3040-8.

[http://dx.doi.org/10.3748/wjg.v16.i24.3040] [PMID: 20572308]

[11] Nabi MS, Waseem T. Pulmonary hydatid disease: what is the optimal surgical strategy? Int J Surg 2010; 8(8): 612-6.

[http://dx.doi.org/10.1016/j.ijsu.2010.08.002] [PMID: 20732461]

[12] Turna A, Yilmaz MA, Haciibrahimoğlu G, Kutlu CA, Bedirhan MA. Surgical treatment of pulmonary hydatid cysts: is capitonnage necessary? Ann Thorac Surg 2002; 74(1): 191-5. [http://dx.doi.org/10.1016/S0003-4975(02)03643-3]

[PMID: 12118757]

[13] Ahmad M, Khan SA, Shah SZ, et al. Effect of size on the surgical management of pulmonary hydatid cyst. J Ayub Med Coll Abbottabad 2014; 26(1): 42-5.

[PMID: 25358215]

[14] Kuzucu A, Ulutas H, Reha Celik M, Yekeler E. Hydatid cysts of the lung: Lesion size in relation to clinical presentation and therapeutic approach. Surg Today 2014; 44(1): 131-6.

[http://dx.doi.org/10.1007/s00595-012-0484-2] [PMID: 23334707]

[15] Usluer O, Ceylan KC, Kaya S, Sevinc S, Gursoy S. Surgical management of pulmonary hydatid cysts: is size an important prognostic indicator? Tex Heart Inst J 2010; 37(4): 429-34 [PMID: 20844615]

[16] Santosh T, et al. Hydatid cyst at unusual locations: Report of two cases. Human Pathology: Case Reports 2017; 8: 59-61.

[17] Salama AA, Othman AA, Zayed HA. Cystic echinococcosis in the middle region of the Nile Delta, Egypt: Clinical and radiological characteristics. Egyptian J Rad Nucl Med 2014; 45(3): 641-9. [http://dx.doi.org/10.1016/j.ejrnm.2014.05.004]

(C) 2020 Ahmadinejad et al.

This is an open access article distributed under the terms of the Creative Commons Attribution 4.0 International Public License (CC-BY 4.0), a copy of which is available at: https://creativecommons.org/licenses/by/4.0/legalcode. This license permits unrestricted use, distribution, and reproduction in any medium, provided the original author and source are credited. 